UCRL-ID-130003

\title{
Contamination Effects on Optical Damage
}

\author{
F. Y. Génin \\ M. R. Kozlowski \\ M. D. Feit
}

This article is a reprint from Chemistry and Materials Science

Progress Report, UCID-20622-97

March 2, 1998

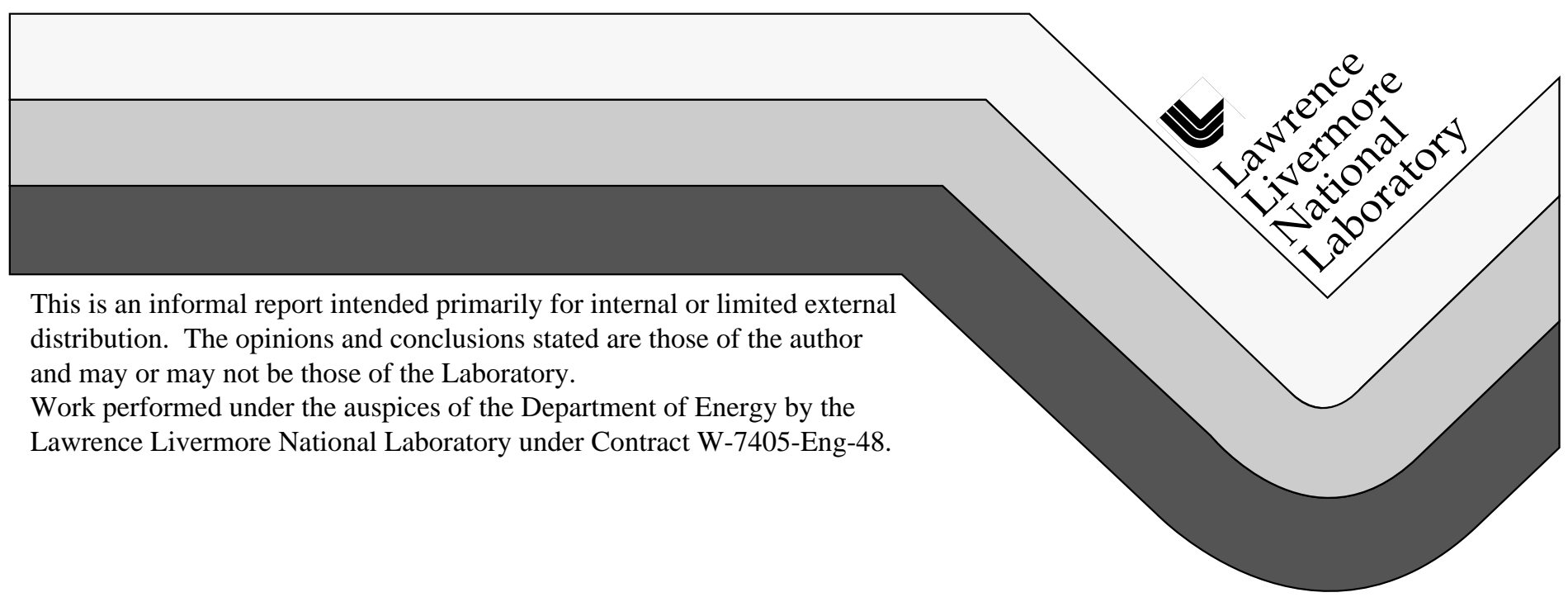




\section{DISCLAIMER}

This document was prepared as an account of work sponsored by an agency of the United States Government. Neither the United States Government nor the University of California nor any of their employees, makes any warranty, express or implied, or assumes any legal liability or responsibility for the accuracy, completeness, or usefulness of any information, apparatus, product, or process disclosed, or represents that its use would not infringe privately owned rights. Reference herein to any specific commercial product, process, or service by trade name, trademark, manufacturer, or otherwise, does not necessarily constitute or imply its endorsement, recommendation, or favoring by the United States Government or the University of California. The views and opinions of authors expressed herein do not necessarily state or reflect those of the United States Government or the University of California, and shall not be used for advertising or product endorsement purposes.

This report has been reproduced directly from the best available copy.

Available to DOE and DOE contractors from the

Office of Scientific and Technical Information

P.O. Box 62, Oak Ridge, TN 37831

Prices available from (615) 576-8401, FTS 626-8401

Available to the public from the

National Technical Information Service

U.S. Department of Commerce

5285 Port Royal Rd.,

Springfield, VA 22161 


\title{
Contamination Effects on Optical Damage
}

\author{
F. Y. Génin, M. R. Kozlowski, and M. D. Feit
}

The development and construction of high fluence lasers for inertial confinement fusion such as the National Ignition Facility (NIF) at Lawrence Livermore National Laboratory (LLNL) or the Laser Mégajoule in France continues to generate strong interest in the behavior of optical components under intense laser irradiation. The design of such lasers has created significant technological challenges in the area of laser glass, KDP crystal growth, surface finishing, and fused silica damage in the ultraviolet (UV). The damage of fused silica lenses at $355 \mathrm{~nm}$ is of particular concern since the optical design requires peak fluences that are very close to the damage threshold of the most resistant fused silica lenses available today.

For years, contamination has been known to degrade the performance of optics and to sometimes initiate laser damage. This study quanitifies these effects at 1064 and $355 \mathrm{~nm}$ for fused silica windows by investigating several contamination cases: particles (thicker than 0.1 $\mu \mathrm{m}$ and larger than $10 \mu \mathrm{m}$ in diameter), very thin films (thinner than $10 \mathrm{~nm}$ ), and "intrinsic" contamination (i.e., caused by polishing). A variety of contamination materials including metals, oxides, and organic compounds were studied and a masking technique was used to produce particles of known size, mass, and shape, with the contaminants deposited by sputtering. To study the damage behavior of the contaminated optics, the laser-induced damage threshold (LIDT) was measured over a statistically representative population of sites, and the damage morphologies were characterized.

\section{Laser-Induced Damage of Polished Surfaces}

Damage of clean polished fused silica was first studied to provide a baseline for comparison with contaminated optics. The polishing process was determined to strongly influence the LIDT. Therefore, the same batch of polished substrates was used for all the tests. The 3-ns LIDT was $14 \mathrm{~J} / \mathrm{cm}^{2}$ with a standard deviation of $1.5 \mathrm{~J} / \mathrm{cm}^{2}$. Scanning electron microscopy (SEM) characterization of the surface damage morphology showed that laser irradiation initiates micrometer-size ellipsoidal pits [see Figure 1(a)]. These pits were found to be the precursors to crack formation at above threshold fluences. The morphology of the cracks depends on the surface (input vs output) where damage occurs [see Figure 1(b) and (c)]. (a)

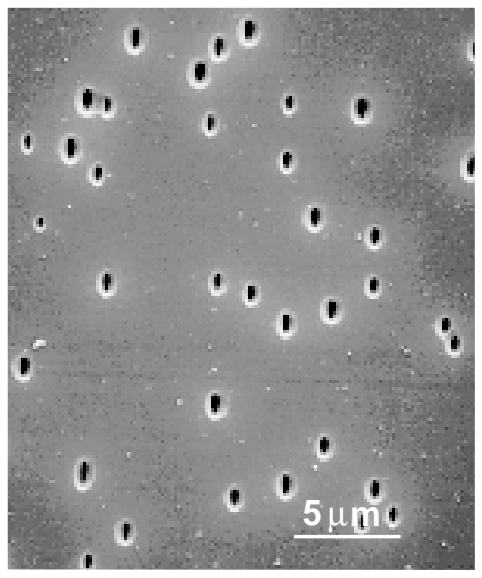

(b)

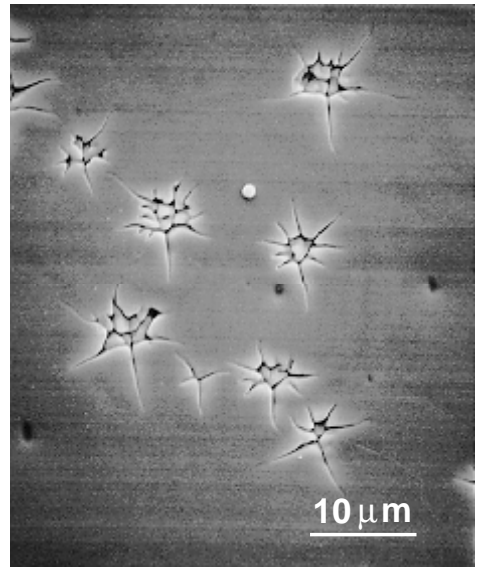

(c)

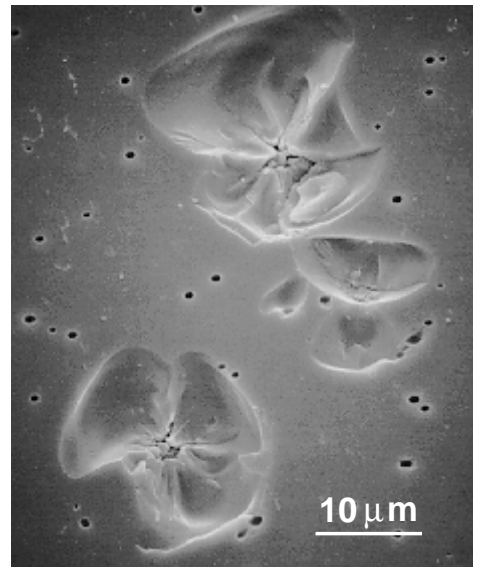

Figure 1. SEM micrographs of damage on the surface after a single shot at $355 \mathrm{~nm}$ : (a) ellipsoidal micro-pits that are the precursors to damage on both input and output surfaces, $(b)$ input surface starlike cracks, and (c) output surface shell-like cracks. Areas which were not irradiated did not exhibit any surface features (or any pits). 


\section{Laser Damage Initiated by Contamination Particles}

The tests in the UV (at $355 \mathrm{~nm}$ ) show that for fluences above $1.5 \mathrm{~J} / \mathrm{cm}^{2}$, a plasma can ignite at the contamination particle. The damage morphologies were very reproducible from particle to particle for the same fluence and size. However, the damage phenomena were different for particles on the input vs output surface (see Figure 2).

Input surface contamination tends to splatter during repetitive illumination, leaving a burnt surface with a large number of small craters. The propagation of light through the area obscured by the particle produced downstream intensity modulations that could catastrophically crack the output surface. These cracks grow easily during repetitive illumination by drilling into the glass. The light diffraction phenomenon at the particle was modeled and compared with experimental measurements of the ablated depth of silica on the output surface (see Figure 3). The model has allowed us to predict the threat to optics due to input surface contamination as a function of its thickness, particle size, and shape.

Output surface contamination is often blown off during the first shot, leaving massive damage behind. However, when the fluence is high or when the pressure wave of the particle exceeds a critical value, a crack can initiate during the laser pulse and catastrophic damage can occur.

Both input and output surface contaminants have, therefore, the potential for initiating catastrophic failure of the output surface at fluences lower than the damage threshold of clean optics. Input surface, however, has more negative effects at $355 \mathrm{~nm}$. Finally, the contamination material was found to have a significant influence on the decrease in LIDT. These effects were modeled using LASNEX calculations and showed reasonable agreement with experiments.

\section{Laser Damage Caused by Thin Films Contamination}

Thin film contamination of $\mathrm{Cu}, \mathrm{Al}, \mathrm{Au}$, and $\mathrm{B}_{4} \mathrm{C}(1,2$, and $5 \mathrm{~nm}$ thick) were studied at $355 \mathrm{~nm}$. Contamination even for the thinnest deposits can reduce the LIDT by a factor of 2 or more. The film material has a strong influence on the damage morphology (see Figure 4). In particular, at the onset of damage, $\mathrm{B}_{4} \mathrm{C}$ leads to a higher density of micro-pits on the surface than a clean damaged surface while metals do not lead to any micropits.

\section{Conclusion}

This study has allowed more quantitative predictions of the potential for damage to optics due to contamination (particles and thin films) on a high fluence laser beamline. The results have provided the experimental basis for setting the cleanliness requirements for NIF optical components to a class 50 cleanroom environment. NIF construction engineers are also applying general rules regarding the choice of construction materials so as to minimize the risk of contamination initiated damage and to allow the NIF laser to operate at its full potential.

\section{Publications}

1. F. Y. Génin, K. Michlitsch, J. Furr, M. R. Kozlowski, and P. Krulevitch, "Laser-Induced Damage of Fused Silica at 355 and 1064 nm Initiated by Aluminum Contamination Particles on the Surface," in Laser-Induced Damage in Optical Materials, SPIE 2966, 126 (1996).

2. F. Y. Génin, M. R. Kozlowski, J. Furr, and R. M. Brusasco, "Massive Laser Damage of Fused Silica at 355 and $1064 \mathrm{~nm}$ Initiated by Surface Contamination," 2nd Annual International Conference on Solid-State Lasers for Application to ICF, Paris, France (1996, in press).

3. M. D. Feit, A. M. Rubenchik, D. R. Faux, R. A. Riddle, A. B. Shapiro, D. C. Eder, B. M. Penetrante, D. Milam, F. Y. Génin, and M. R. Kozlowski, "Modeling of Laser Damage Initiated by Surface Contamination," in Laser-Induced Damage in Optical Materials, SPIE 2966, 417 (1996).

4. F. Y. Génin, M. D. Feit, A. Salleo, A. M. Rubenchik, M. R. Kozlowski, and J. Yoshiyama, "UV Laser Ablation of Glass Enhanced by Contamination Particles," COLA 97 (Fourth International Conference on Laser Ablation), Monterey, CA. 
Typical $355 \mathrm{~nm}$ damage morphology for copper
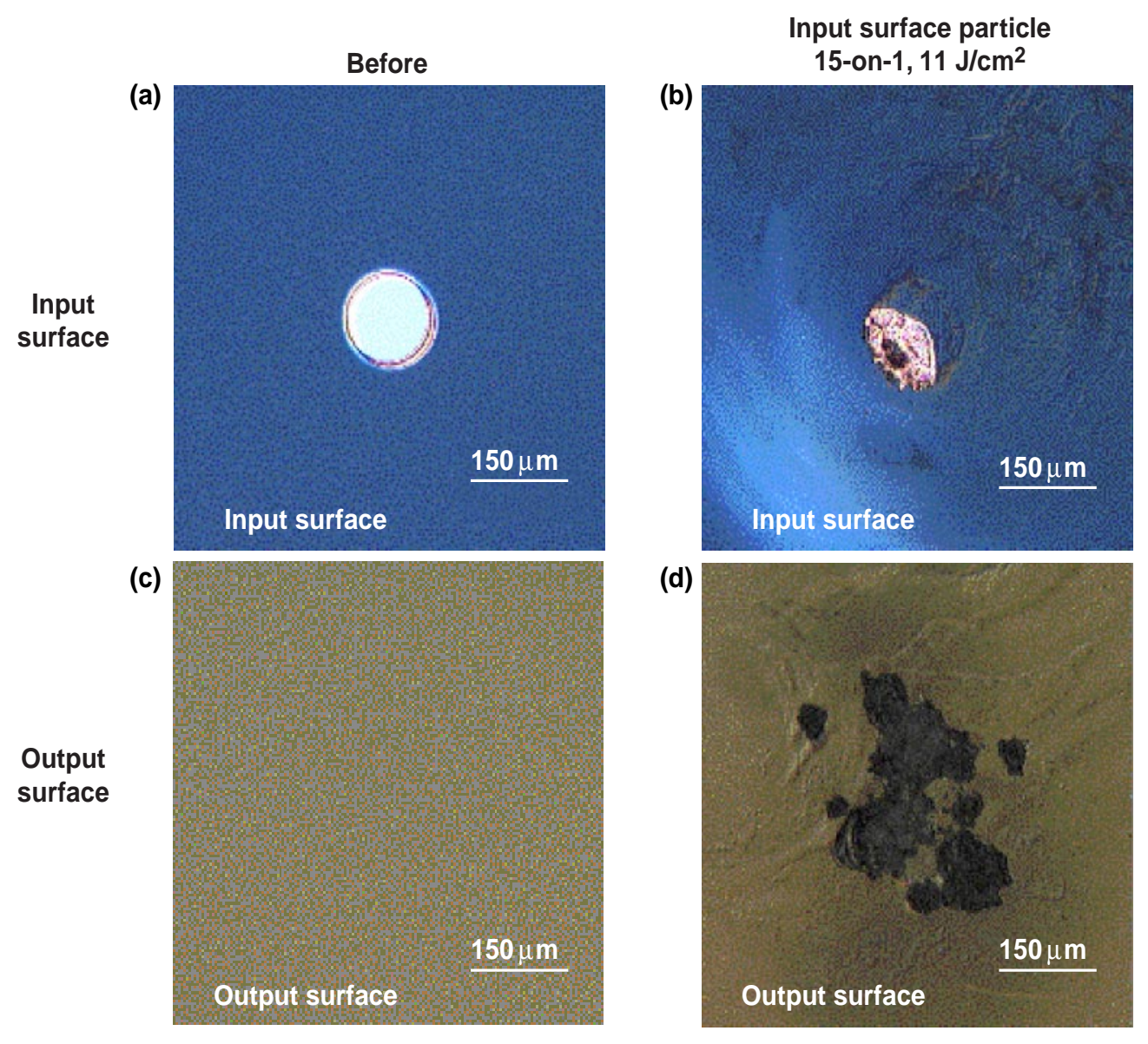

(d)

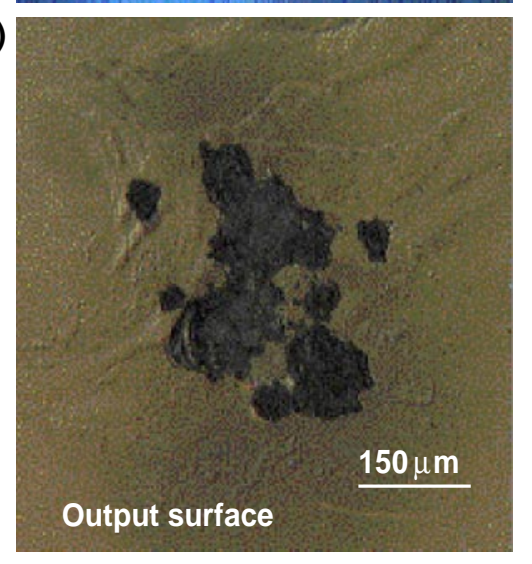

Before

\section{Output surface particle}

2-on-1, $14 \mathrm{~J} / \mathrm{cm}^{2}$

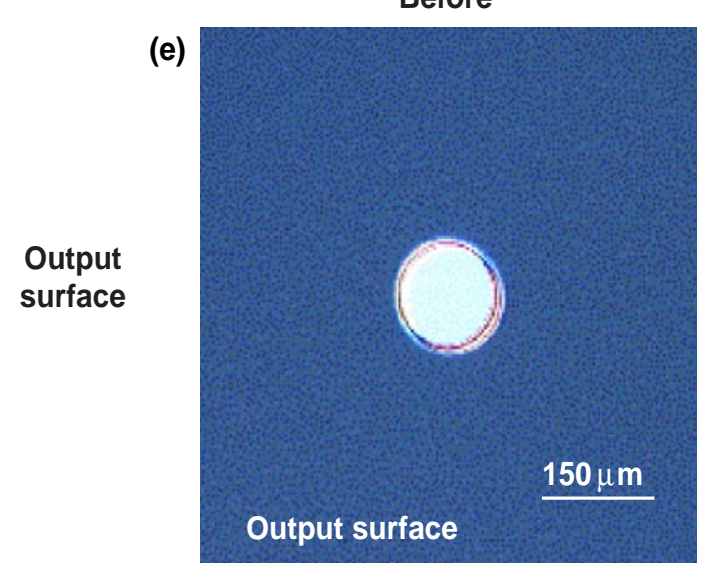

(f)

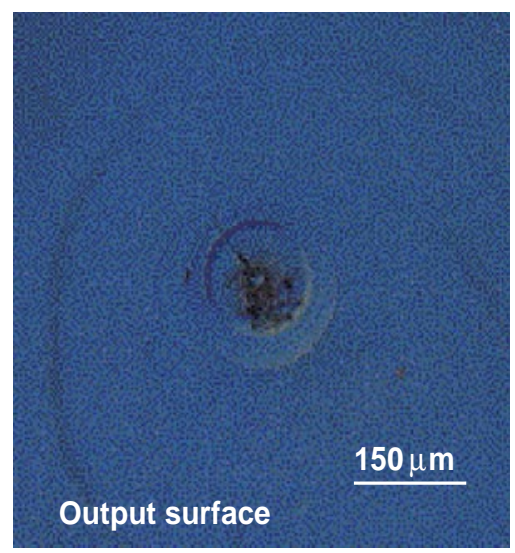

Figure 2. Input surface contamination. Nomarski optical micrographs: (a) 1- $\mu \mathrm{m}$-thick, 150- $\mu \mathrm{m}$-diam $\mathrm{Cu}$ particle on the input surface before irradiation; (b) input surface damage after 15 shots at $355 \mathrm{~nm}$ and $11 \mathrm{~J} / \mathrm{cm}^{2}$; (c) output surface before illumination; and (d) after the 15 shots. Output surface contamination. Nomarski optical micrographs: (e) particle on the output surface before irradiation and (f) crack formation at the particle after two shots at $355 \mathrm{~nm}$ and $13.5 \mathrm{~J} / \mathrm{cm}^{2}$. In both cases, the surface damage was catastrophic. 
(a)

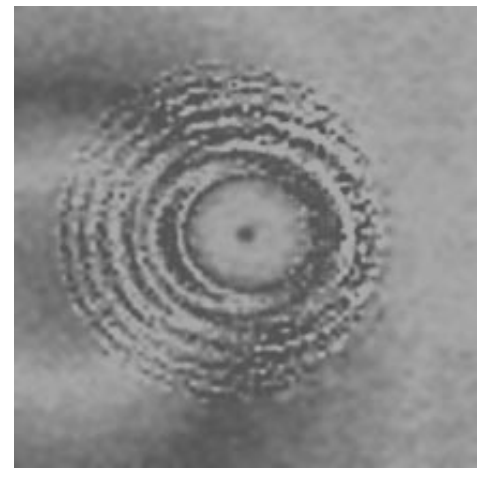

(b)

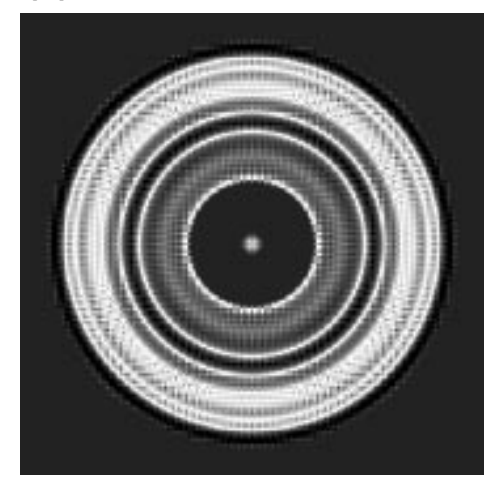

(c)

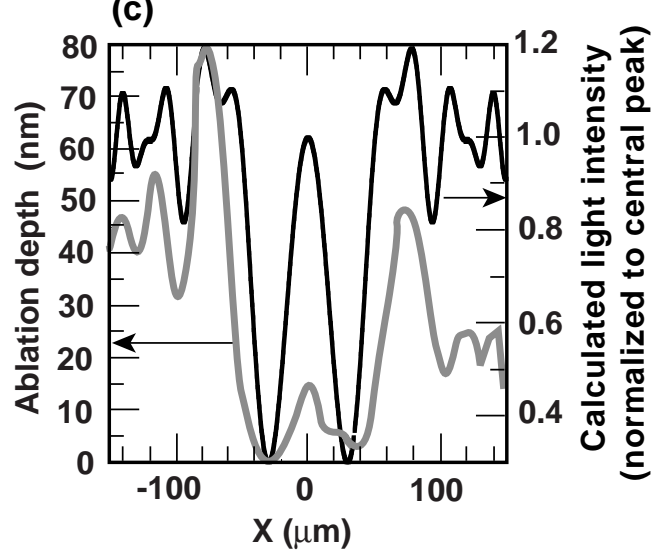

Figure 3. (a) Optical interference micrograph of output surface damage caused by a 1- $\mu \mathrm{m}$-thick, $50-\mu \mathrm{m}$-diam Ti circular particle located on the input surface; (b) Calculated profile of the light intensity modulations caused by a $50-\mu \mathrm{m}$-diam obscuration located $11 \mathrm{~mm}$ upstream; and (c) Comparison between the experimentally measured depth of ablated silica and the calculated intensity modulation. The modeled and experimental profiles show very good agreement.

(a) Bare surface

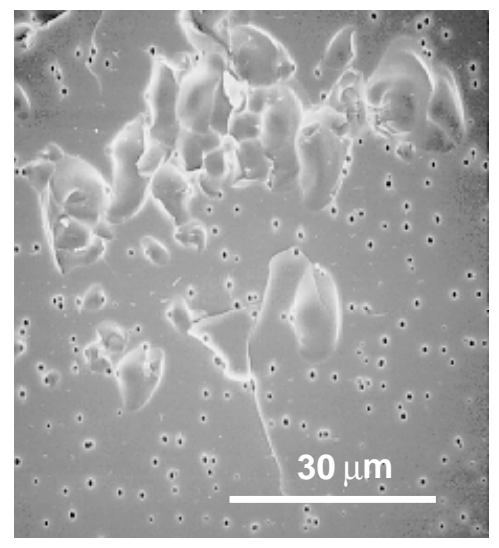

(b) $50 \AA \mathrm{Cu}$

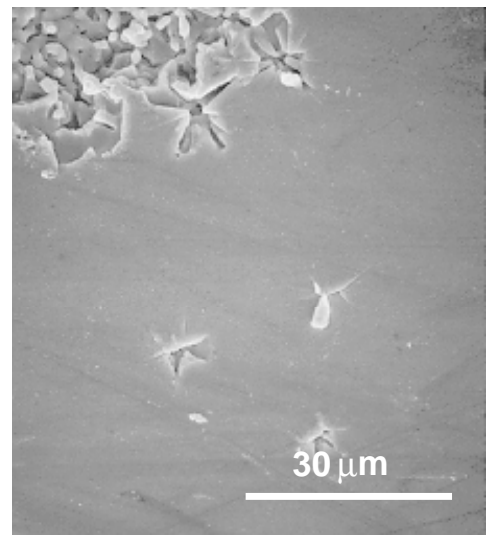

(c) $20 \AA \mathrm{B}_{4} \mathrm{C}$

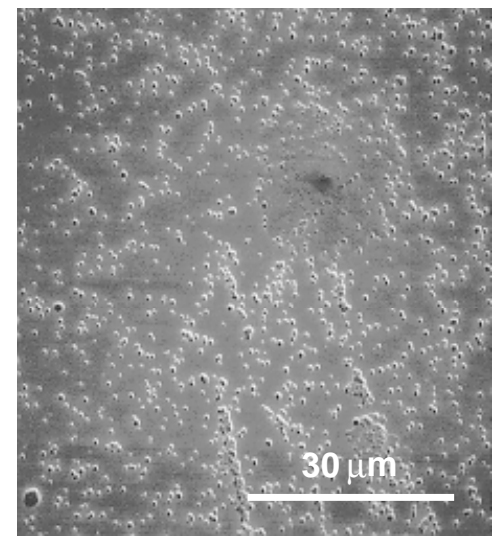

Figure 4. SEM micrographs of output surface damage on (a) a contamination-free surface and initiated by a thin contamination film on the output surface, (b) $5 \mathrm{~nm} \mathrm{Cu}$, and (c) $2 \mathrm{~nm} \mathrm{~B}_{4} \mathrm{C}$ after a single shot at $12 \mathrm{~J} / \mathrm{cm}^{2}$. 


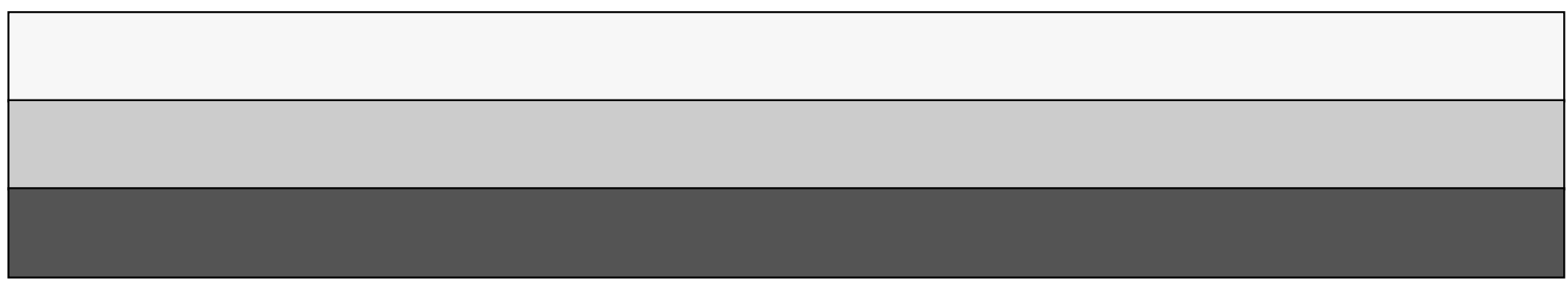

